\section{CONTRIBUTIONS TO LARYNGOLOGY.}

Reai in the Section of Laryngology and Otology, at the Fortieth An nial Meeting of the American Medical Association, /une, 1889 .

BY EPHRAIM CUTTER, M.D., LL.D., OF NEW YORK.

I. AN OLD CASE OF THYROTOMY, I866, SUCCESSFUL, 1889 .

In I 866 I performed what was called thyrotomy modified-that is, by the disuse of tracheotomy or tube for the removal of a large sarcoma which nearly filled the calibre of the larynx. It was necessary to make new vocal and breath bands by the scissors. An account was published in the American Journal of Medical Science, December, I866. This case is living and phonates well. She can also sing a few notes of the middle register. This case has also an interest in the light of a recent report of the results of thyrotomy by Dr. Hoppa, of Warrburg. He collected ro4 cases done since 1879. Four cases died after the operation ; 100 cases were cured, as far as the operation was concerned. He found eighteen recoveries with normal voice out of thirty-eight. Sixty per cent. of Dr. Hoppa's cases had normal voice, and some sang.

The youngest case that the writer operated on was a child of twenty-two months. Here a tracheotomy tube was used. The growth was very voluminous, and new vocal and breath bands had to be made by scissors. Voice was restored, but death from cholera infantum followed soon after. The writer agrees with Dr. Hoppa that the operation is desirable.

\section{TWO CASES OF FIBROID ENLARGEMENT OF THE ARYTENOID CARTILAGES.}

Case I.-Résumé after twenty-one years' lapse since treated. Permanent recovery.

In February, I868, Prof. H. M. Field, M.D., of Dartmouth College, placed under my care Mrs. G. $\mathrm{H}$. Jones, of Newton, Mass. She was a middle-aged lady, apparently in good health, but was annoyed by irritation in the throat, cough, and difficulty of swallowing; her health otherwise was good. On examination I found the throat and larynx healthy, with the exception of the left arytenoid cartilage, which stood up with its tip enlarged, obovoid, the long diameter vertical, side diameter half an inch, and about three-quarters of an inch long. It resembled very much the hard rubber and ivory bougies which are used to dilate the strictures of the cesophagus. The surface was covered with a faintly colored mucous membrane, through which shone the white, pearly, lustrous body of the enlargement, very much as the cartilages of the ribs appear at an autopsy.

It appeared to be of a cartilaginous, or what I now call a fibroid structure. There was no evidence of tuberculous disease, though at that time I had not learned how to detect consumption in the blood as I do now; still, I am not prepared to say it might not have been tuberculous. In this case I was confronted with a lesion I had never heard of, and was thrown on my own resources as to treatment. I gave the matter considerable thought, and being influenced by the good results of free incisions in tissues in the other parts of the body, which were indurated to that extent that $I$ then felt as if foreign substances were imbedded in them, I resolved to try the effect of free incisions upon the growth.

Not satisfied with the knives I had, because they were not simple enough, I had one made by Codman \& Shurtleff, the whole length of which, handle and all, was $101 / 2$ inches ; length of handle, 3 inches; length of shaft of knife, which was rounded and tapering, 5 inches. At the distal end of the shaft there was a piece $21 / 2$ inches long joined to the shaft by an angle of $I I^{\circ}$. The upper part of the short piece was round and cylindrical; the lower part was flattened in a direction parallel to the long axis of the instrument; on one side near its point it was flat, and on the other beveled in two planes, coming down to a blunt, flattened point.

With this knife I made free scarifications under the laryngoscopic mirror, so that one or two mouthfuls of blood would be expectorated at each sitting. There was so much relief experienced at these sittings, that the patient was willing and ready to accommodate my best judgment. The sittings averaged two a week, if my memory serves me rightly, for three months. The enlargement began gradually to grow less, till finally it was as small as its neighbor on the other side.

In a letter dated Newton, January 9, I889, she writes: "Since then" (the operation) "there has been no return of the trouble. Of course when I take cold my throat is a little sensitive. Very truly yours, Mrs. G. H. Jones."

Case 2.-Not long after the first case was treat. ed, though I am not sure about the date, an Irishman, Currier, thin, nervous, about 25 years of age, applied to me about difficulty in his throat. He was bothered about swallowing, and said he had a valve growing in his throat which sometimes choked him. His circumstances in life were such that he was not well fed or nourished, and he was impecunious, lacking, of course, the care which case I had, whose every want was supplied with loving attention. If anything, this growth was slightly larger than the other, more globular and movable on its base, so that it must have interfered with the respiration, especially during sleep. Indeed, his sleep was broken so much that he began to run down.

Both of these patients could swallow, but with some difficulty. Taking advantage of the experience gained in case $\mathrm{I}$, the growth was subjected to the same treatment; but owing to the mobility of its base and, I think, the increased density of 
its substance combined, I was unable to penetrate so deeply as in case I; nor could I procure so much blood from one scarification as in the other case. As the man grew weaker his difficulty was increased, so much so that I feared he would lose his life by strangulation, and with the consent of the patient and friends I decided to perform tracheotomy and introduce a tube. I did so. My assistants at the operation wished me to tuse ether, while I preferred chloroform. I told them that the moment he inhaled ether the secretions of the salivary and parotid glands would be started to such an extent that when he became insensible the secretions would run into the larynx, cause a spasm of the glottis, and the patient would suffocate instantly, just as people drown from the inhalation of water into the larynx when they are submerged. But they refused to assist me unless ether was employed, and as I did not see how I could do the operation without their assistance I yielded to their influence; but what has been described as likely to happen, did happen in exactly that way. The man took the ether well, but the moment the secretions of the oral cavity ran into his larynx he ceased to breathe instantly and, curiously, his heart stopped beating. I was then obliged to make my incision without regard to blood, cutting down in great haste, feeling my knife with my finger, to know where I was cutting, laid bare the rings of the trachea, separated the tissues with my fingers, and cut through. In consequence the blood went into the trachea. I put the tube in, but that filled with blood, and having no other means at hand I placed my lips on the tube and sucked the blood out, and the respiration was established, greatly to the gratification of all present. For myself, I told the gentlemen I could have done the operation secundum artem, but was obliged to do the best I could. I would not recommend the use of ether in such circumstances. The case went on like other cases of tracheotomy. The man was very comfortable; the growth seemed to be arrested by the relief given to the air passages. $\mathrm{He}$ remained under my care for about three months, when he went to Ohio on a visit. There he met some medical gentleman who, I think, was not a laryngologist, for he told the patient that the tube was of no use and should be removed. He removed it, and very soon, I was told, the man died. In this way I lost my patient and my tube.

Remarks. - If I were to meet such cases again, with the scarification, I would use the Salisbury plan of diet for fibroid tumors, and I might apply the galvanic current. In my opinion these lesions are trophopathic, and I think that trophopathy (trophos, food, and pathos, disease) should be the basis of treatment for all throat diseases, organic or functional.

\section{A NEW NAME PROPOSED FOR THE VENTRICL- IAR BANDS.}

The writer has studied his own larynx since I862, inspecting his vocal bands, ventricular bands, arytenoid cartilages, during phonation, cantation from $F$ below in the bass cleff to $G$. above in the treble cleff, and during laughing, coughing, sneezing, respiration and deglutition; but it was not till $\mathrm{r} 884$ that he had a clear idea of the function of the ventricular bands, more commonly called "false vocal cords." To be sure he had traced the alarming, clangorous, peculiar cough in spasmodic croup to the thickening, probably almost odematous, condition of the ventricular bands. A young lady about i 8 years old, apparently well, would at times exhibit this "croupal" cough. When this cough came on in school it excited, at first, alarm in teacher and scholars all over the room. When the cough was produced under the laryngoscope, the contact of the ventricular bands was trifid, dividing the ventricular plane into three equal parts, like a circular disc cut into three equal portions. This was a unique curiosity, and seems to explain the peculiar tussive cough by the chronically swelled condition of the ventricular bands.

The ventricular bands are the chief physical agents in producing cough by holding the breath back and fixing the diaphragm so that it presses the air forcibly against the closed ventricular bands, which, suddenly and instantly relaxed, allow the air to rush forth as if projected from a weapon, and thus the explosive sound is produced which we call cough, and the outgoing air expels whatever secretions may have been borne upwards by the ciliæ of the bronchial and tracheal epithelia to where the air can reach. From this function in cough the ventricular bands might be called "cough" bands or chords.

But their chief function in health is the holding of the breath. Professor C. W. Emerson, Ph.D., principal of the Monroe School of Oratory, Boston, lately stated to his pupils "that for many years he had taught that the vocal cords were the chief agents in holding the breath, and not the rigid setting of the abdominal muscular walls and diaphragm; that in normal breathing the vocal bands close for an instant during expiration, and the action of the diaphragm and of the abdominal muscles thus arrested forces the inspired air into the apices of the lungs, expanding them in a normal manner and supplying fresh air, and that thus the full development of the upper chest was obtained and maintained in speaking and singing; that in unhealthy respiration the vocal cords did not close and hold the air, and that hence flat, weak chests and weak voices were the natural consequences of the unresisted outgo; that when he came across some articles on the subject ${ }^{1}$ he found it was not the 
vocal cords, but the ventricular bands, that did this work of arrest." After this statement the writer demonstrated on himself the fact that the ventricular bands close in order to hold the breath during phonation, cantation, etc., and that, so far as can be seen, the vocal bands have a rest during this function of holding the breath, which is of the greatest importance to speakers and singers who wish to do efficient work, and, to bring the subject home, to the medical man who reads a paper and to the audience who is listening to him.

In 1884 the writer appealed to professional laryngologists to give a new name to the false vocal cords, or ventricular bands; but as he has heard of no response to this appeal he ventures now to suggest some names for approval, premising that the word "chords," or "cords," is not expressive enough of the situation; for to do so one has to imagine a cello $D$ string about $\mathrm{I} / 2$ inches long, split longitudinally into two equal parts, a section of the end being a semicircle, the rounded side of the string forming the band, and the squared side prolonged or towards the walls of the larynx. Imagine a string like this. How little music it would make! The fact is, the nearest analogy to the vocal bands is found in the lips of a cornet player, stretched over the embouchure of the mouth-piece; only the vocal bands are joined in front and opened behind, while the lips of the cornet player are joined at each side. The vocal bands are made tense by the stretching backwards of the arytenoid cartilages, etc., while the lips are stretched over the circular ring of the mouth-piece. Players speak of "making a lip," but singers and speakers "make their glottis", instinctively.

The ventricular bands are ill named, because the ventricles they form with the vocal bands are accidental things, and not important functions of which we have spoken, to wit: the proper holding of the breath in respiration, phonation, cantation, sneezing, etc. Suppose we follow the nomenclature "vocal bands," then we might call the ventricular bands ( 1 ) breath bands, (2) breath holders, (3) breath cords, (4) breath valves, (5) breath lips.

If, instead of the vocal bands for the true vocal cords, we say "voice bands," then the writer would prefer for the false vocal cords, "breath bands," until some one else favors us with a better name; but as false vocal cords have gone, so shall ventricular bands go, as being inexpressive of the functions of the important mucous membrane, red-colored processes or bands, that form the middle of the three valves of the larynx, to wit: (I) the epiglottis, (2) breath bands, (3) voice bands.

I (a) Gaillard's Medical Journal, October, 1884 ; (b) Transactions Music Teachers' National Association (America), 1887 ; (c) Transactions Ninth International Medical Congress, 1887 , vol. iv, pp. 305-IIt.
The closing of one after the other, beginning with valve 3 , Dr. Frederick Semeleder, now of Mexico, showed beautifully in 1862, during the function of swallowing.

The Ariston, Broadway and 55th street, June, 1889.

\section{LAPAROTOMY FOR PERFORATING TYPHOID ULCER. \\ BY REED B. BONTECOU, M.D., OF TROY, N. Y.}

On October 26 , 1889 , I was called in consulta. tion with Dr. St. John, of Centre Brunswick, to see Arthur P. Dater, a farmer, æt. 27, living near Millville, some miles from Troy, in a healthy district, and with comfortable surroundings. I learned from his physician, Dr. St. John, that he had been suffering from typhoid fever for some forty days past, having had a relapse after the first twenty days of illness, and that at two A.M. on the day of my visit he had been suddenly seized with symptoms of peritonitis. We found him in a state of moderate collapse, pulse very frequent, skin bathed in perspiration, abdomen tympanitic, tense, and an absence of liver dulness. Intestinal perforation was diagnosed, and the chances of life with or without operation fairly stated to his family and himself, and with their consent and his own I proceeded, about 7 P.M., with artificial light, with strict antiseptic precautions, to the operation, assisted by Dr. St. John and my son, Dr. R. Brinsmade Bontecou. A median incision, three or four inches in length, was made, and on opening the peritoneum a gush of gas, followed by a quantity of brownish, muddy serum, escaped. The small intestines were distended and vividly red; the distal portion of the ilium was at once sought for and readily found, and presented a circular perforation of about three-sixteenths of an inch in diameter in one of the Peyerean patches, some four or five inches from the ileo-cæcal valve, through which yas and feculence were escaping. Several of the patches in the lower twelve or eighteen inches of the intestine were much enlarged and thickened, and presented bright red spots on the peritoneal surface, as if threatening perforation. But no other openings were found, and I turned in the ulcer. ated patch in a transverse fold, being unable to make one longitudinally on account of the thickened mass of glandular tissue, which, if treated in that manner, would have diminished the lumen of the intestine too much. The rupture was covered in by a Lembert continuous suture, and after irrigating the peritoneal cavity thoroughly with boiled water, I closed the wound around a large sized rubber drainage-tube (having no glass ones with me), which I had doubled, the bend being within the cavity. Iodoform was freely dusted 